\title{
Combination chemotherapy in rheumatoid arthritis
}

\author{
P M Brooks, A C Schwarzer
}

Over the past 20 years considerable research has been carried out on the pathophysiology of joint destruction in rheumatoid arthritis. Although the precise primary cause of the disease is not known, the complex events of cellular activation, mediator production, and consequent cartilage destruction have been elucidated. ${ }^{1-3}$ There is an increased realisation among rheumatologists that early treatment of rheumatoid arthritis with suppressive agents is essential if cartilage is to be protected from irreversible damage by the inflammatory synovitis. Unfortunately, despite the use of slow acting antirheumatic drugs (SAARDs), long term studies suggest significant morbidity and mortality. Mitchell et al followed up 805 patients with rheumatoid arthritis over a 12 year period and showed that their survival from the time of diagnosis was about half that of population controls. ${ }^{4}$ In that study treatment with gold and prednisolone did not influence mortality, except that there was a clustering of deaths from vasculitis within the group receiving prednisolone. Similiar results have been shown by other workers. ${ }^{5-7}$ Scott et al studied 112 patients with rheumatoid arthritis treated for 20 years with single SAARDs. ${ }^{7}$ By 20 years over half of the patients were either dead $(35 \%)$ or severely disabled (19\%).

Significant morbidity also occurs in patients with rheumatoid arthritis. ${ }^{89}$ Pincus et al showed that over $90 \%$ of a group of 75 patients with rheumatoid arthritis reviewed nine years after the initial evaluation had significant impairment of functional ability and that work disability occurred in $85 \%$ of those under the age of 65 who had been working full time at disease onset. ${ }^{8}$ It would seem that the time has come when we need to ask ourselves exactly what we are trying to achieve when suppressing rheumatoid inflammation and why our present approaches seem to be failing. There are a number of reasons why long term results of treatment for rheumatoid arthritis are so poor: (a) we might not be using appropriate drugs that really do 'switch off the synovitis; $(b)$ perhaps we are using them too late-after irreversible damage has already occurred to cartilage, which might in itself perpetuate inflammation; $(c)$ if these drugs do work patients might not be able to continue taking them for sufficient periods of time because of side effects; (d) the disease process might be too complex for any single agent to deal with.

One of the major problems with the use of SAARDs seems to be the inability of patients to continue taking them for long periods of time. Thompson et al in a retrospective study of 247 case notes, using life table analysis, showed that about $60 \%$ of patients responded to a first or second SAARD and did so within six months. ${ }^{10}$ The response to a third SAARD was as low as $30 \%$, however. Long term (five years or more) studies of SAARDs in rheumatoid arthritis suggest that less than $50 \%$ of patients are taking gold, D-penicillamine, sulphasalazine, or antimalarial drugs five years after the start. ${ }^{11-15}$ Patients whose disease was initially controlled by these agents ceased taking the drugs because of either the development of side effects or a flare in disease activity, despite continuation of the treatment. Furthermore, success with one course of an SAARD does not guarantee that the patient will respond to that drug a second time. In a study of gold treatment Evers and Sundstrom showed that only $36 \%$ of patients with a good initial response to gold achieved complete remission with the second course. $^{16}$

Despite the enthusiastic use of SAARDs by rheumatologists there seems to be no clear consensus as to whether these drugs really do reduce the rate of cartilage erosion in the long term. ${ }^{17}$ Some studies have shown a reduction in the progression of erosions in the short term with gold, ${ }^{18}{ }^{19}$ sulphasalazine, ${ }^{20}$ cyclophosphamide, ${ }^{21}$ and methotrexate, ${ }^{22}{ }^{23}$ but, on the other hand, a number of studies have failed to show any significant influence of SAARDs on radiological progression. ${ }^{24-26}$

In view of the poor results with existing treatment it would seem necessary to rethink the approach to rheumatoid arthritis. As pointed out above, rheumatoid arthritis can no longer be considered a benign disease. The rheumatoid pannus behaves in a similar fashion to a locally invasive neoplasm, ${ }^{27-29}$ showing the need for earlier and more aggressive treatment. The argument for early treatment is clear as Brook and Corbett have shown that in up to $90 \%$ of those patients who develop erosive rheumatoid disease radiographic changes are apparent in the first two years. ${ }^{30}$ The poor long term results in most clinical studies might reflect delayed treatment of rheumatoid arthritis initiated after this critical early period. Many rheumatologists have now abandoned the traditional 'therapeutic pyramid', and some even propose reversing this with a 'step down bridge' approach of combined drugs, which are stopped sequentially as the disease is controlled. ${ }^{31}$ As the pathogenetic processes of rheumatoid arthritis are so complex it is extremely unlikely that any single agent will block all the pathways leading to joint destruction. It might, therefore, be reasonable to consider using combinations of drugs, either simultaneously or cyclically, in a similar fashion 
to the use of immunosuppressive agents in the treatment of some malignant diseases.

The aim of combination therapy is to improve efficacy while minimising side effects. By combining drugs with different modes of action, it is hoped that additive or synergistic effects might be achieved. Several factors have retarded our progress in the search for successful combinations of SAARDs. Firstly, there is the issue of toxicity and, in particular, myelotoxicity. This might have such devastating consequences that rheumatologists are loath to combine agents with myelotoxic potential. Secondly, like many new treatments, these combinations have been used in patients who have severe disease, numerous single agents having failed in the past. Using this approach, we might well select a subset of patients who are unlikely to respond to any drug that we offer, ${ }^{24}$ and the results of the trial might not reflect the type of responses that might be obtained if the combinations were used at an early stage in disease.

There are now increasing numbers of published reports illustrating the efficacy of combination therapy in rheumatoid arthritis. Many of these studies, however, are open, uncontrolled, or retrospective or of short duration with inadequate patient numbers. McCarty and Carrera reported the use of a combination of cyclophosphamide, azathioprine, and hydroxychloroquine in 17 patients with severe refractory rheumatoid arthritis. ${ }^{32}$ After a mean follow up of 27 months five patients had achieved a complete remission and radiographs showed recortication of erosions in nine patients. Side effects were a major problem in this study as the follow up data showed. ${ }^{33}$ Although 16 of 31 patients achieved a complete remission after a mean treatment period of 31 months, four patients developed neoplasia and only six patients reported no adverse events. Although there have been over 30 reports of the use of combination therapy in the treatment of rheumatoid arthritis, ${ }^{34}$ only three of these were randomised, double blind studies. ${ }^{33-35}$

The major randomised studies of combination therapy in rheumatoid arthritis are summarised in the table. From these studies it would seem that some combinations-gold and D-penicillamine, gold and hydroxychloroquine, and gold and sulphasalazine-are more effective than the drugs used alone. They were however, fairly short term studies. In a recent study from our own group patients with severe rheumatoid arthritis refractory to other SAARDs were treated with continuous prednisolone and hydroxychloroquine and alternating treatment periods of one month of methotrexate or sulphasalazine. ${ }^{42}$ Significant improvements in clinical and laboratory variables occurred at three months but by 12 months the only parameters which still showed improvement were the pain score, erythrocyte sedimentation rate, and the Ritchie index. Half of the patients had withdrawn by 12 months: half because of lack of efficacy and half because of side effects.

Carefully conducted clinical trials of combination therapies used early in an effort to try to arrest the disease process are clearly required. Careful attention to clinical trial design ${ }^{4344}$ should be made and the patients followed up for a significant period of time. The mechanism of action and spectrum of side effects of the drugs to be used in combination should also be considered carefully.

Other drugs are available to control different aspects of joint damage and they should be considered in any combination therapy. For example, little attention has been paid to drugs which might protect cartilage from damage, such as orgotein, ${ }^{45}$ glycosaminoglycan polysulphate (Arteparon), ${ }^{4647}$ and Rumalon. ${ }^{47} 48$ Although these studies were carried out in osteoarthritis, there is evidence to show that they protect cartilage from breakdown by inflammation in some animal models. ${ }^{49} 50$ As one of the major aims of treatment in rheumatoid arthritis should be to protect cartilage these so called chondroprotective agents should also be considered as part of the combinations to be tested in the treatment of rheumatoid arthritis. We must continue to strive for new approaches for the treatment of rheumatoid arthritis, including the development of antibodies directed at critical aspects of immune responses, such as interleukin 2 receptor antibodies, ${ }^{51}$ anti-CD4 antibodies, ${ }^{52}$ and antithymocyte globulin. ${ }^{53} \mathrm{We}$ should also, however, be thinking of different ways of using drugs we already have in an effort to stem the tide of inflammatory synovitis.

PMB is supported by the Arthritis Foundation of Australia.

1 Cavender D, Haskard D, Yu-C-L, et al. Pathways to chronic inflammation in rheumatoid synovitis. Federal Proceedings 1987; 46: 113-7.

2 Forrest M J, Brooks P M. Mechanism of action of nonsteroidal anti-inflammatory drugs. Baillieres Clin Rheumatol steroidal anti-inflam

3 Harris E D. Rheumatoid arthritis: pathophysiology and implications for therapy. $N$ Engl $\mathcal{f}$ Med 1990; 322: 1277-89.

4 Mitchell D M, Spitz P W, Young D Y, Bloch D A, McShane

Combination therapy in rheumatoid arthritis

\begin{tabular}{|c|c|c|c|}
\hline Ref & Combination & $\begin{array}{l}\text { Number } \\
\text { of patients }\end{array}$ & Results \\
\hline Double blind, randomised & $\begin{array}{l}\text { ad, randomised } \\
\text { D-Penicillamine and hydroxychloroquine }\end{array}$ & 56 & Combination not as effective as D-penicillamine alone. \\
\hline 36 & Gold and D-penicillamine & 45 & $\begin{array}{l}\text { Combination resulted in earlier response than gold or } \\
\text { D-penicillamine alone }\end{array}$ \\
\hline 37 & Gold and hydroxychloroquine & 101 & Combination more effective than gold and placebo \\
\hline $\begin{array}{l}\text { Non- } \\
38\end{array}$ & $\begin{array}{l}d, \text { randomised } \\
\text { Gold and D-penicillamine, levamisole or } \\
\text { chlorambucil }\end{array}$ & 71 & $\begin{array}{l}\text { D-Penicillamine and gold effective, other combinations } \\
\text { ineffective }\end{array}$ \\
\hline 39 & $\begin{array}{l}\text { Methotrexate, cyclophosphamide, and } \\
\text { hydroxycholoroquine }\end{array}$ & 18 & Combination effective. Recortication of erosions \\
\hline $\begin{array}{l}40 \\
41\end{array}$ & $\begin{array}{l}\text { D-Penicillamine and sulphasalazine } \\
\text { D-Penicillamine and chloroquine }\end{array}$ & $\begin{array}{l}30 \\
72\end{array}$ & $\begin{array}{l}\text { Combination more effective than sulphasalazine alone } \\
\text { No advantage of combination } v \text { either drug alone }\end{array}$ \\
\hline
\end{tabular}


D J, Fries J F. Survival, prognosis and causes of death in rheumatoid arthritis. Arthritis Rheum 1986; 29: 706-14

5 Rasker J J, Cosh J A. Cause and age at death in a prospective study of 100 patients with rheumatoid arthritis. Ann Rheum Dis 1981; 40: 115-20.

6 Vollertsen R S, Conn D L, Ballard D J, Ilstrup D M, Kazmar R E, Silverfield J C. Rheumatoid vasculitis: survival and associated risk factors. Medicine (Baltimore) 1986; 65: 365-75.

7 Scott D L, Symmons D P M, Coulton B L, Popert A J. Long erm outcome of treating rheumatoid arthritis. Results after 20 years. Lancet 1987; i: 1108-11.

8 Pincus T, Callahan L F, Sales W G, Brooks A L, Payne L E, Vaughn $\mathbf{W}$ K. Severe functional declines, work disability and increased mortality in seventy-five rheumatoid arthritis patients studied over nine years. Arthritis Rheum 1984; 27 864-72.

9 Kaarela K, Lehtinen K, Luukkainen R. Work capacity of patients with inflammatory joints diseases. Scand $\mathcal{J}$ Rheumatol 1987; 16: 403-6.

10 Thompson P W, Kirwan J R, Barnes C G. Practical results of treatment with disease-modifying antirheumatoid drugs. $\mathrm{Br}$ treatment with disease-modifying

11 Situnayake R D, Grindulis K A, McConkey B. Long term treatment of rheumatoid arthritis with sulphasalazine, gold, or penicillamine: a comparison using life table methods. Ann Rheum Dis 1987; 46: 177-83.

12 Bentzon $M$ W, Gad I, Halberg $\mathrm{O}$, et al. Influence of previous gold treatment and other patient variables on outcome of treatment with disease modifying antirheumatic drug (DMARD) in patients with rheumatoid arthritis. Clin Rheumatol 1986; 5: 39-48.

13 Husain Z, Runge L A. Treatment complications of rheumatoid arthritis with gold, hydroxychloroquine, D-penicillamine and levamisole. I Rheumatol 1980; 7: 825-30.

14 Veys E M, Mielants H, Verbruggen G. Gold salts, levamisole and D-penicillamine as first choice slow acting antirheumatic drugs in rheumatoid arthritis-a long term follow-up study. Clin Exp Rheumatol 1987; 5: 111-6.

15 Rothermich N O, Philips V K, Bergen W, Thomas M H. Chrysotherapy: a prospective study. Arthritis Rheum 1976 19: 1321-7.

16 Evers A E, Sundstrom W R. Second course gold therapy in the treatment of rheumatoid arthritis. Arthritis Rheum 1983 26: $1071-5$.

17 Wright V, Amos R. Do drugs alter the course of rheumatoid arthritis? BMF 1980; 280: 964-6.

18 Sigler J W, Bluhm G B, Duncan H, Sharp J T, Ensign D C McCrum R. Gold salts in the treatment of rheumatoid arthritis. A double blind study. Ann Intern Med 1974; 80: $21-6$.

19 Lulikainen R, Kajander A, Isomaki H. Effect of gold on progression of erosions in rheumatoid arthritis. Scand $\mathcal{J}$

20 van der Heidje D $M$, van Riel P L, Nuver-Zwart I H, Gribnau $F W$, van der Putte L B. Effects of hydroxy chloroquine and sulphasalazine on progression of joint damage in rheumatoid arthritis. Lancet 1989; i: 1036-8.

21 Co-operating clinics of the North American Rheumatism Association. A controlled trial of cyclophosphamide in rheumatoid arthritis. $N$ Engl f Med 1970; 283: 883-9.

22 Kremer J M, Lee J K. A long term prospective study of the use of methrotrexate in rheumatoid arthritis. Arthritis Rheum 1988; 31: 577-84.

23 Weinblatt M E, Trentham D E, Fraser P A, et al. Long term prospective trial of low dose methotrexate in rheumatoid arthritis. Arthritis Rheum 1988; 31: 167-75.

24 Scott D L, Coulton B L, Chapman J H, Bacon P A, Popert A J. The long term effects of treating rheumatoid arthritis. $\mathcal{F}$ Coll Physicians Lond 1983; 17: 79-88.

25 Pullar T, Hunter J A, Capell H A. Does second-line therapy affect the radiological progression of rheumatoid arthritis? Ann Rheum Dis 1984; 43: 18-23.

26 Spector T D, Scott D L. What happens to patients with rheumatoid arthritis? The long term outcome of treatment. Clin Rheumatol 1988; 7: 315-30.

27 Ehrlich G E. Heroic treatment for non malignant disease. JAMA 1982; 248: 1743-4.

28 Hamilton J A. Hypothesis: in vitro evidence for the invasive and tumour-like properties of the rheumatoid pannus. f R heumatol 1983; 10: $845-51$.

29 Sebalt R F. Pulse steroid therapy and the search for improved drug therapy of rheumatoid arthritis. $\mathcal{F}$ Rheumatol 1988 15: $200-1$.
30 Brook A J, Corbett $M$. Radiographic changes in early rheumatoid arthritis. Ann Rheum Dis 1977; 36: 71-3.

31 Healey L A, Wilske K R. Reforming the pyramid. A plan for treating rheumatoid arthritis in the 1990s. Rheum Dis Clin North Am 1989; 15: 615-9.

32 McCarty D J, Carrera G F. Intractable rheumatoid arthritis: treatment with combined cyclophosphamide, azathioprine treatment with combined cyclophosphamide, azathioprine

33 Csuka M E, Carrera G F, McCarty D J. Treatment of intractable rheumatoid arthritis with combined cyclophosphamide, azathioprine and hydroxychloroquine: a follow up study. FAMA 1986; 255: 2315-9.

34 Schwarzer A C, Arnold M H, Brooks P M. Combination therapy in rheumatoid arthritis. Baillieres Clin Rheumatol $1990 ; 4: 663-85$

35 Bunch T W, O'Duffy J D, Tompkins R B, O'Fallon W L. Controlled trial of hydroxychloroquine and $\mathrm{D}$-penicillamine singly or in combination in the treatment of rheumatoid arthritis. Arthritis Rheum 1984; 27: 267-76.

36 McKenna F, Hopkins R, Hinchcliffe K P, Bird H A, Wright $V$. Gold and penicillamine, alone and in combination in active rheumatoid arthritis [Abstract]. Proceedings of the 16th international congress of rheumatology, Sydney. 1985: 158 .

37 Scott D L, Dawes P T, Tunn E, et al. Combination therapy with gold and hydroxychloroquine in rheumatoid arthritis: a prospective, randomised placebo controlled study. $\mathrm{Br} \mathcal{F}$ Rheumatol 1989; 28: 128-33.

38 Bitter T. Combined disease-modifying chemotherapy for intractable rheumatoid arthritis. Clinics in Rheumatic Diseases 1984; 10 : 417-28.

39 Butler D, Tiliakos N. Low dose cytotoxic drug-combination therapy in intractable rheumatoid arthritis. Arthritis Rheum 1985; 28: 515 .

40 Taggart A J, Hill J, Astbury C, Dixon J S, Bird H A, Wright V. Sulphasalazine alone or in combination with D-penicillamine in rheumatoid arthritis. Br $\mathcal{f}$ Rheumatol 1987; 26: $32-6$

41 Gibson T, Emery P, Armstrong R D, Crisp A J, Panayi G S. Combined D-penicillamine and chloroquine treatment in rheumatoid arthritis. A comparative study. $\mathrm{Br} \mathcal{F}$ Rheumatol 1987; 26: 279-84.

42 Schwarzer A C, Arnold M H, Kelly D, et al. Cycling combination antirheumatic drug therapy in rheumatoid arthritis. Br 7 Rheumatol 1990; 29. 445-50.

43 Kirwan J R, Currey H L F. Rheumatoid arthritis: Disease modifying anti-rheumatic drugs. Clinics in Rheumatic modifying anti-rheumatic
Diseases 1983; 9: 581-99.

44 Katain J S, Hochberg M C. Clinical trials: a guide to understanding methodology and interpreting results. understanding methodology and

45 Mcllwain H, Silverfield J C, Cheatum D E, et al. Intraarticular orgotein in osteoarthritis of the knee: a placebocontrolled efficacy, safety and dosage comparison. Am Med f 1989; 87: 295-300.

46 Ishikawa K, Kitagawa T, Tanaka T, et al. Clinical evaluation of the intra-articular injection of glycosaminoglycan polysulphate for osteoarthritis of the knee joint. Z Orthop 1982; 120: 708-16.

47 Rejholec V. Long term studies of antiosteoarthritic drugs: an assessment. Semin Arthritis Rheum 1987; 17: 35-53

48 Dixon A St J, Kersley G D, Mercier R, et al. A double-blind controlled trial of Rumalon in the treatment of painful
osteoarthritis of the hip. Ann Rheum Dis 1970; 29: 193-4.

49 Francis D J, Forrest M J, Brooks P M, Ghosh P. Retardation of articular cartilage degradation by glycosaminoglycan polysulphate (Arteparon), pentosan polysulphate (SP54) and $\mathrm{DH} 40 \mathrm{~J}$ in the rat airpouch model. Arthritis Rheum 1989; 32: 608-16.

50 Burkhardt D, Ghosh P. Laboratory evaluation of antiarthritic drugs as potential chondroprotective agents. Semin Arthritis Rheum 1987; (suppl 1): 3-34.

51 Kyle V, Coughlan R J, Tighe H, Waldmann H, Hazleman B L. Beneficial effect of monoclonal antibody to interleukin 2 receptor on activated T cells in rheumatoid arthritis. Ann Rheum Dis 1989; 48: 428-9.

52 Herzog C, Walker C, Muller W, et al. Anti-CD4 antibody treatment of patients with rheumatoid arthritis. Effect on clinical course and circulating T cells. F Autoimmun 1989; 2: $627-42$.

53 Shmerling R H, Trentham D E. Prolonged improvement in refractory rheumatoid arthritis after antithymocyte globulin therapy of brief duration. Arthritis Rheum 1989; 32: $1495-6$ 